\title{
Improved Mass Resolving Power and Yield in Atom Probe Tomography
}

\author{
D.J. Larson, T.J. Prosa, J. H. Bunton, D. Olson, D. Lawrence, E. Oltman, S. N. Strennen and \\ T.F. Kelly
}

Cameca Instruments Inc., 5500 Nobel Drive, Madison, WI 53711 USA

Thin coatings have long been applied to atom probe tomography (APT) specimens in order to 1) study the materials science of the coatings or the specimen/coating interface [1-4] or 2) improve the conductivity of the specimen [5-6]. The current work presents progress in using multilayer coatings designed to increase the thermal and/or optical properties of the overall specimen + coating system in order to improve yield [7] and APT mass resolving power (MRP).

Amorphous $\mathrm{SiN}$ was chosen for this study as it has relatively poor thermal conductivity (and thus low thermal diffusivity) which results in long "thermal tails" in the mass spectrum and reduced mass resolution [8]. Specimens were examined under three post-focused-ion-beam-prepared conditions: 1) uncoated $\mathrm{SiN}$, 2) Pd-coated $\mathrm{SiN}$, and 3) Ag/Pd-coated SiN (as shown in Fig. 1). Pd was used as an adhesion layer for the Ag coating [9]. Deposition conditions for the monolithic Pd films were 30 minutes at $45^{\circ}$ (relative to specimen axis) using a SBT ion beam sputter system. The bilayer film deposition conditions were 10 minutes at $60^{\circ}$ for $\mathrm{Pd}$ and 40 minutes at $60^{\circ}$ for $\mathrm{Ag}$. Specific depths were not calibrated due to the deposition occurring on the continuously curved surface of the specimen. The APT data collection parameters were: specimen temperature $20 \mathrm{~K}$, laser energy per pulse $50 \mathrm{pJ}, 500 \mathrm{kHz}$ pulse rate, detection rate of one ion detected every 200 pulses.

A comparison of $\mathrm{Si}^{++}$mass spectra for $35 \mathrm{~nm}$ by $35 \mathrm{~nm}$ by $60 \mathrm{~nm}$ volumes $(\sim 2$ million ions in each volume) is shown in Fig. 2 for uncapped $\mathrm{SiN}$ and for $\mathrm{Pd} / \mathrm{Ag}$ capped $\mathrm{SiN}$. The mass spectral quality for the coated SiN specimen is improved, mainly on the trailing edge of the peaks. These results were reproducible (Fig. 3) as shown by mean values for mass resolving power measured at onehundredth maximum: $16 \pm 5,35 \pm 9$, and $83 \pm 15$ for the uncoated (three runs), Pd-coated (four runs), and $\mathrm{Pd} / \mathrm{Ag}$-coated (four runs) specimens. These results show an improvement of approximately a factor of five for the mass resolving power in the "tail" region of the mass spectrum when comparing the uncoated and $\mathrm{Pd} / \mathrm{Ag}$-coated specimen types. In addition to the improvements in MRP, there is indication that the $\mathrm{Pd} / \mathrm{Ag}$ coating improves specimen yield. Fig. 4 shows total ion counts for the same 11 datasets presented in Fig. 3. Larger ion counts were obtained for the $\mathrm{Pd} / \mathrm{Ag}$-coated specimens as compared to the other two cases for all specimens run under identical conditions. The "peak-to-background" ratio (defined as counts within a 0.1 Da range at the main peak divided by the counts in the tail ranged out to the base noise level) for a $\mathrm{Pd} / \mathrm{Ag}$-coated $\mathrm{SiN}$ specimen vs. an uncoated specimen is shown in Fig. 5. Both magnitude and uniformity of this metric are improved (note the same total range scale of 0.10 used for both plots). Fig. $5 \mathrm{~b}$ is relatively isotropic compared to Fig. 5a, suggesting that the coating results in in more uniform heat flow following the laser pulse.

1. M. J. Southon et al., Surf. Sci. 53 (1975) 554

2. $\quad$ S. V. Krishnaswamy et al., Appl. Phys. Lett. 35 (1979) 870.

3. T. Sakurai, R.J. Culbertson and A.J. Melmed, J. Vac. Sci. Technol. 16 (1979) 626.

4. T. Jeske, G. Schmitz and R. Kirchheim, Mat. Sci. Engr. A 270 (1999) 64.

5. G. L. Kellogg, J. Appl. Phys. 53(9) (1982) 6383.

6. A. J. Melmed et al., J. de Phys 47-C7 (1986) 333.

7. S. Duguay (2011) Unpublished.

8. J. H. Bunton et al., Micro. Microanal. 13 (2007) 418.

9. D. J. Larson et al., Ultramicroscopy 111 (2011) 506. 

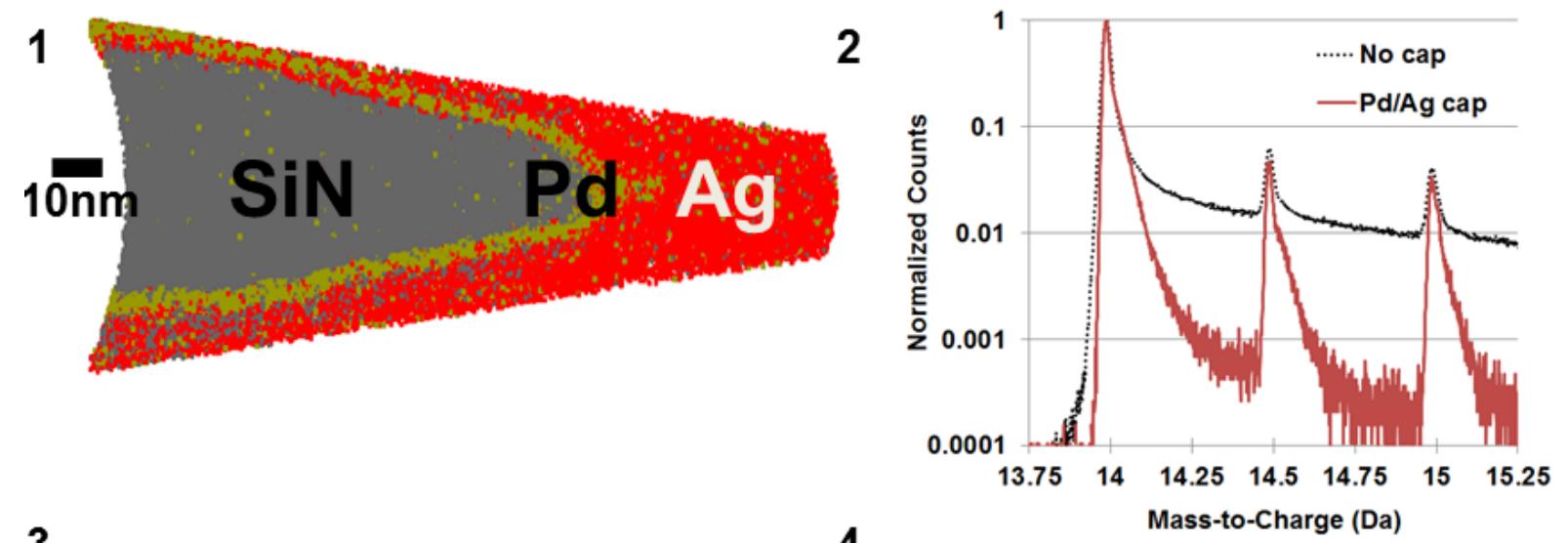

3
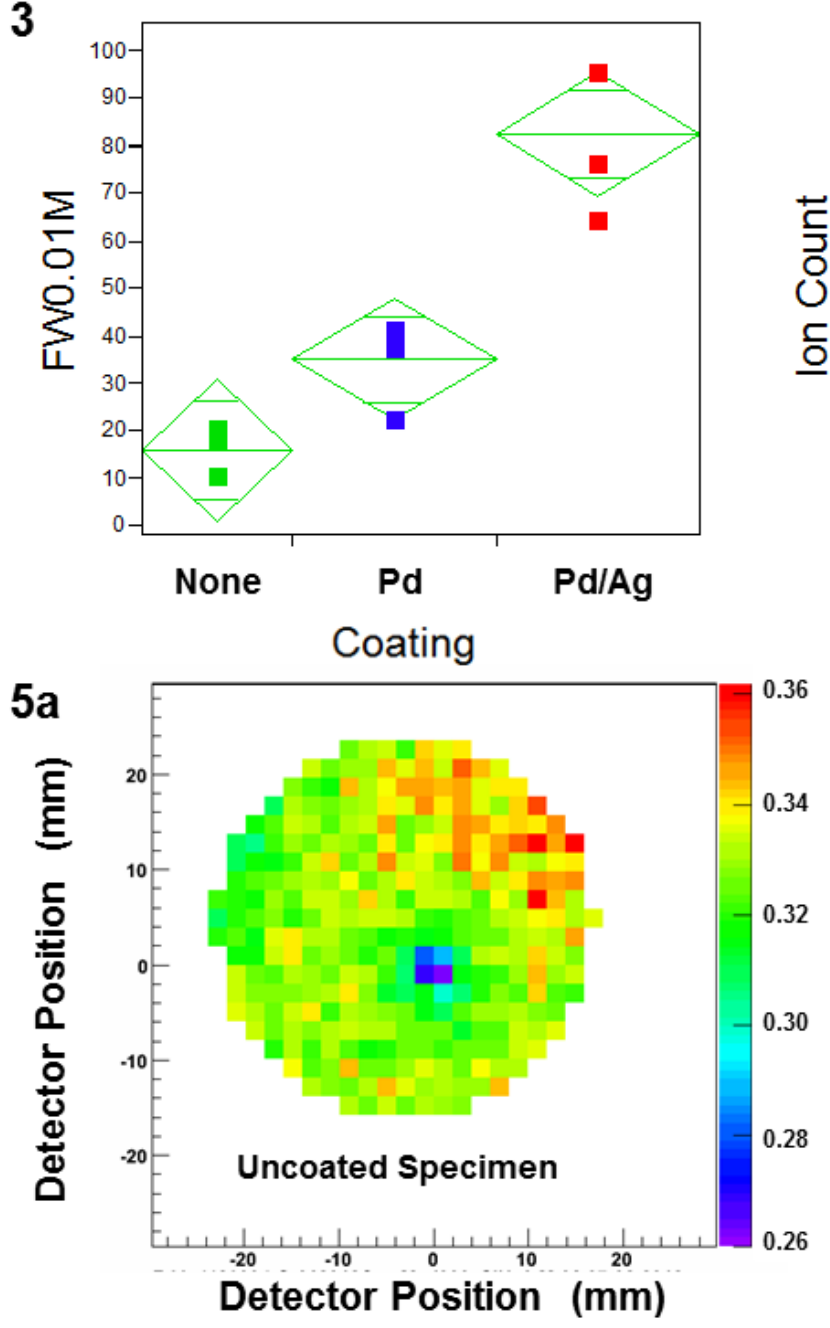

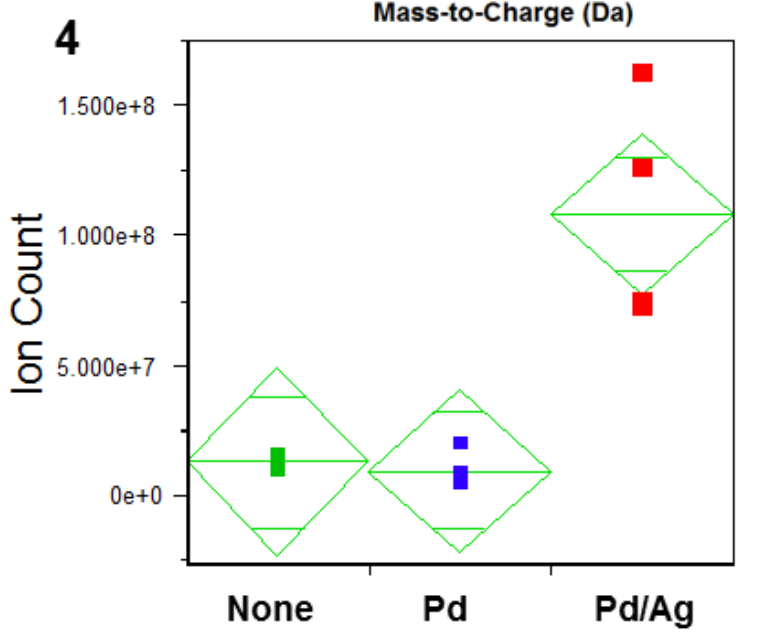

Coating

$5 b$

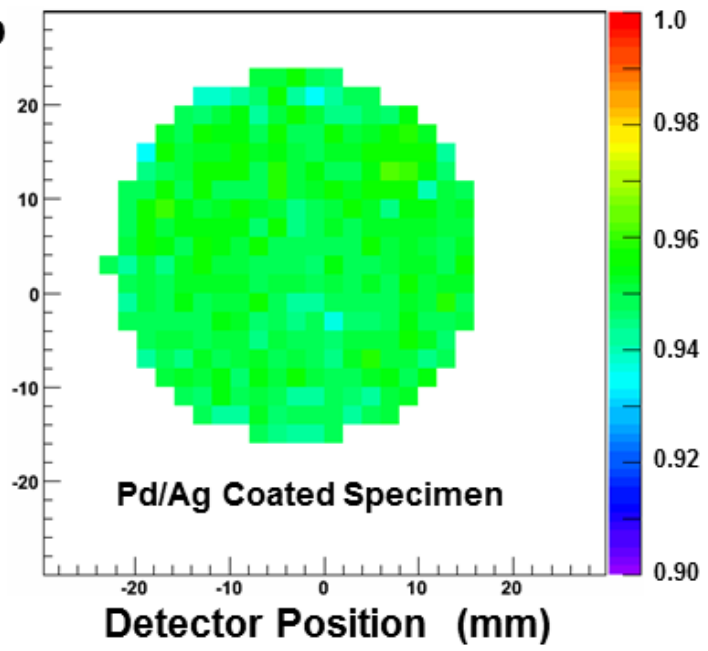

Fig. 1. Atom map of a SiN specimen prepared by focused ion beam milling and coated with $\mathrm{Pd} / \mathrm{Ag}$. Fig. 2. Mass spectra from a coated (solid line) versus an uncoated SiN specimen (dashed line).

Fig. 3. Mean mass resolving power for uncoated, Pd-coated, and Pd/Ag-coated SiN. respectively (note that the upper and lower tips of the mean diamonds show the $95 \%$ confidence interval).

Fig. 4. Ion count from uncoated, Pd-coated, and Pd/Ag-coated SiN APT data.

Fig. 5. Peak-to-background counts ratio for the $\mathrm{Si}++$ peak at $14 \mathrm{Da}$ for the (a) the uncoated $\mathrm{SiN}$ specimen and (b) Pd/Ag coated SiN specimen. Note the same scale total range (0.10) for both plots. 